\title{
Evaluation of response to stereotactic radiosurgery in patients with radioresistant brain metastases
}

\author{
Mutlay Sayan1, Teuta Zoto Mustafayev², Bilgehan Sahin², Erva Seyma Sare Kefelioglu ${ }^{3}$, Shang-Jui Wang ${ }^{1}$, \\ Varsha Kurup ${ }^{1}$, Aykut Balmuk ${ }^{4}$, Gorkem Gungor ${ }^{2}$, Nisha Ohri', Joseph Weiner ${ }^{1}$, Enis Ozyar ${ }^{2}$, Banu Atalar ${ }^{2}$ \\ 'Department of Radiation Oncology, Rutgers Cancer Institute of New Jersey, New Brunswick, NJ, USA \\ ${ }^{2}$ Department of Radiation Oncology, School of Medicine, Mehmet Ali Aydinlar Acibadem University, Istanbul, Turkey \\ ${ }^{3}$ Institute of Health Sciences, Mehmet Ali Aydinlar Acibadem University, Istanbul, Turkey \\ ${ }^{4}$ School of Medicine, Mehmet Ali Aydinlar Acibadem University, Istanbul, Turkey
}

Purpose: Renal cell carcinoma (RCC) and melanoma have been considered 'radioresistant' due to the fact that they do not respond to conventionally fractionated radiation therapy. Stereotactic radiosurgery (SRS) provides high-dose radiation to a defined target volume and a limited number of studies have suggested the potential effectiveness of SRS in radioresistant histologies. We sought to determine the effectiveness of SRS for the treatment of patients with radioresistant brain metastases.

Materials and Methods: We performed a retrospective review of our institutional database to identify patients with RCC or melanoma brain metastases treated with SRS. Treatment response were determined in accordance with the Response Evaluation Criteria in Solid Tumors.

Results: We identified 53 radioresistant brain metastases (28\% RCC and 72\% melanoma) treated in 18 patients. The mean target volume and coverage was $6.2 \pm 9.5 \mathrm{~mL}$ and $95.5 \% \pm 2.9 \%$, respectively. The mean prescription dose was $20 \pm 4.9 \mathrm{~Gy}$. Forty lesions (75\%) demonstrated a complete/partial response and 13 lesions (24\%) with progressive/stable disease. Smaller target volume $(p<$ $0.001)$, larger SRS dose $(p<0.001)$, and coverage $(p=0.008)$ were found to be positive predictors of complete response to SRS.

Conclusion: SRS is an effective management option with up to $75 \%$ response rate for radioresistant brain metastases. Tumor volume and radiation dose are predictors of response and can be used to guide the decision-making for patients with radioresistant brain metastases.

Keywords: Radiosurgery, Radioresistant, Renal cell carcinoma, Melanoma, Brain

\section{Introduction}

Brain metastasis is the most common intracranial malignancy in adults [1]. Up to $50 \%$ of patients with renal cell carcinoma (RCC) or melanoma develop brain metastases during the course of their disease $[2,3]$. Standard treatment for patients with brain metastases includes external beam radiation therapy; however, RCC and melanoma brain metastases have been traditionally perceived to be 'radioresistant' to external beam whole brain radiation therapy (WBRT) compared to other

Received 20 July 2019, Revised 31 October 2019, Accepted 03 December 2019.

Correspondence: Mutlay Sayan, Department of Radiation Oncology, Rutgers Cancer Institute of New Jersey, 195 Little Albany Street, New Brunswick, NJ 08901, USA. Tel: +1-732-235-2465, Fax: +1-732-253-3953, E-mail: ms2641@cinj.rutgers.edu (http://orcid.org/0000-0002-0101-0951)

(c) This is an Open Access article distributed under the terms of the Creative Commons Attribution Non-Commercial License (http://creativecommons.org/ licenses/by-nc/4.0/) which permits unrestricted non-commercial use, distribution, and reproduction in any medium, provided the original work is properly cited.

www.e-roj.org 
histologies [4-7].

Stereotactic radiosurgery (SRS) has become a preferred treatment option in the initial management of patients with limited brain metastases. Randomized trials have demonstrated that SRS provides higher tumor control and preserves neurocognition compared to WBRT [8-11]. While radioresistant histologies, including $R C C$ and melanoma, were underrepresented in these randomized trials, several retrospective studies have shown that radioresistant brain metastases have local control rates similar to those from non-radioresistant histologies when treated with SRS [1216]. Unfortunately, these retrospective studies used outdated methodologies to assess local control, which may have contributed to the wide range of reported rates of local control from different institutions.

Since the definition of local control varies across studies, factors associated with improved local control in radioresistant brain metastases with SRS have not been established. In this study, we reviewed our experience with SRS in patients with radioresistant brain metastases from primary RCC and melanoma using a modern assessment technique to measure response rates and performed a detailed analysis of factors associated with response rate.

\section{Materials and Methods}

We conducted an IRB-approved retrospective cohort study including all patients with newly diagnosed brain metastases between 2009 and 2018 who underwent SRS at Acibadem Maslak Hospital (IRB No. 2019116). The study was conducted in accordance with the principles of the Declaration of Helsinki. Patients treated with surgery and/or WBRT alone were excluded. Patients without radiographic follow-up and those who had re-irradiation with SRS were not included.

Demographic, clinical, and brain lesion information was collected, including age, gender, location of brain metastases, number of brain metastases, tumor size, tumor volume, addition of WBRT, prescription dose, coverage, and volume receiving a dose of at least $10 \mathrm{~Gy}$ and $12 \mathrm{~Gy}\left(\mathrm{~V}_{\text {10Gy }}\right.$ and $\mathrm{V}_{12 \mathrm{~Gy}}$ respectively).

All patients were treated with a robotic linear acceleratorbased SRS, CyberKnife stereotactic radiosurgery unit (CyberKnife Inc., Sunnyvale, CA, USA). The target volumes were identified on magnetic resonance imaging (MRI) scans that were fused with treatment planning computed tomography (CT). The gross tumor volume (GTV) was delineated as contrastenhancing tumor demonstrated on MRI. The planning target volume (PTV) was generated by a uniform expansion of $1 \mathrm{~mm}$ from the GTV. Doses were prescribed to isodose lines that were $70 \%-90 \%$ such that $95 \%$ of the target volume (PTV) is conformally covered by $100 \%$ of the prescription dose. If there was a critical structure which constraint cannot be met than the PTV coverage allowed be compromised. AAPM TG 101 report was used for all plans and normal tissue dose constraints. For tumors $<2 \mathrm{~cm}$ we tend to treat in 1 fraction, but for larger tumors $(>2 \mathrm{~cm}$ ) or tumors adjacent the critical structures such as brainstem the treatment is delivered in 3-5 fractions.

Patients received post-treatment MRI 4-6 weeks after SRS and were subsequently followed with imaging every three months. Tumor response was classified into categories (complete response, partial response, progressive disease, or stable disease) based upon the percent change in volume evaluated on MRI in accordance with the Response Evaluation Criteria in Solid Tumors (RECIST) [17].

The primary endpoint was to determine the occurrence of complete/partial response rate with SRS. To compare variables between the case and control group, chi-square test, Fisher exact test or t-test were used. Variables of interest were evaluated by univariate logistic regression. Survival analysis was evaluated with Kaplan-Meier survival analysis and logrank test. We examined variables in the proportional hazard analysis (Cox model), to identify the independent predictors of survival. A p-value less than 0.05 was considered statistically significant.

\section{Results}

We identified 53 brain metastases from primary melanoma or RCC treated with SRS in 18 patients (7 females and 11 males) at our institution from 2009 to 2018. The primary tumor was melanoma in 13 patients (72\%) and RCC in 5 patients (28\%). Median follow-up was 10.4 months (range, 3.4 to 37.8 months). Median patient age was 52 years (range, 30 to 84 years). Median Karnofsky Performance Score was 90 (range, 80 to 100). The most common locations were frontal (34\%) and parietal lobes (34\%), followed by temporal (26\%) and occipital lobes (6\%). The mean prescription dose was 2,000 cGy (range, 1,000 to 2,700) in 1 to 5 fractions (median, 1 fraction). Treatment doses for most lesions were prescribed to isodose lines $\geq 80 \%$. WBRT was received by $33 \%$ of the patients either before or after SRS (Table 1).

Overall survival was not significantly different in patients with complete/partial response versus progressive/stable 
Table 1. Demographic and clinical characteristics of the patients included in the study $(n=18)$

\begin{tabular}{|c|c|}
\hline Characteristic & Value \\
\hline Number of brain lesion & 53 \\
\hline Age (yr) & $52(30-84)$ \\
\hline \multicolumn{2}{|l|}{ Histology } \\
\hline $\mathrm{RCC}$ & $19(36)$ \\
\hline Melanoma & $34(64)$ \\
\hline \multicolumn{2}{|l|}{ Location } \\
\hline Lt. frontal & $11(21)$ \\
\hline Rt. frontal & $7(13)$ \\
\hline Lt. parietal & $11(21)$ \\
\hline Rt. parietal & $7(13)$ \\
\hline Lt. temporal & $10(19)$ \\
\hline Rt. temporal & $3(7)$ \\
\hline Lt. occipital & $2(3)$ \\
\hline Rt. occipital & $2(3)$ \\
\hline \multicolumn{2}{|l|}{ Radiation therapy } \\
\hline WBRT & $6(33)$ \\
\hline Dose (cGy) & $3,000 \pm 0$ \\
\hline \multicolumn{2}{|l|}{ SRS } \\
\hline Dose (cGy) & $2,000 \pm 487$ \\
\hline PTV volume (mL) & $6.2 \pm 9.5$ \\
\hline Coverage $(\%)$ & $95.5 \pm 2.9$ \\
\hline$V_{10 G y}(\mathrm{~mL})$ & $24.2 \pm 31.7$ \\
\hline $\mathrm{V}_{12 \mathrm{~Gy}}(\mathrm{~mL})$ & $18.2 \pm 25.2$ \\
\hline \multicolumn{2}{|l|}{ SRS response } \\
\hline Complete response & $31(58)$ \\
\hline Partial response & $9(17)$ \\
\hline Progressive disease & $4(8)$ \\
\hline Stable disease & $9(17)$ \\
\hline
\end{tabular}

Values are presented as median (range) or number (\%) or mean \pm standard deviation.

RCC, renal cell carcinoma; WBRT, whole brain radiation therapy; SRS, stereotactic radiosurgery; PTV, planning target volume.

disease (mean, 12.6 vs. 11.1 months; $p=0.374$ ) (Fig.1). According to the Cox proportional hazards analysis, extracranial metastases on presentation (hazard ratio [HR] = $1.404,95 \%$ confidence interval $[\mathrm{Cl}], 1.169-1.639 ; \mathrm{p}=0.003)$ and the progression of the disease $(\mathrm{HR}=1.023 ; 95 \% \mathrm{Cl}$, $1.03-1.043 ; p=0.016$ ) had a significant impact on survival. However, neither patient's age $(\mathrm{HR}=0.021 ; 95 \% \mathrm{Cl}, 0.006$ $0.036 ; p=0.156)$ nor SRS response $(\mathrm{HR}=0.635 ; 95 \% \mathrm{Cl}$, $1.03-1.043 ; p=0.125$ ) had a significant impact on survival.

Forty lesions (75\%) demonstrated a complete/partial

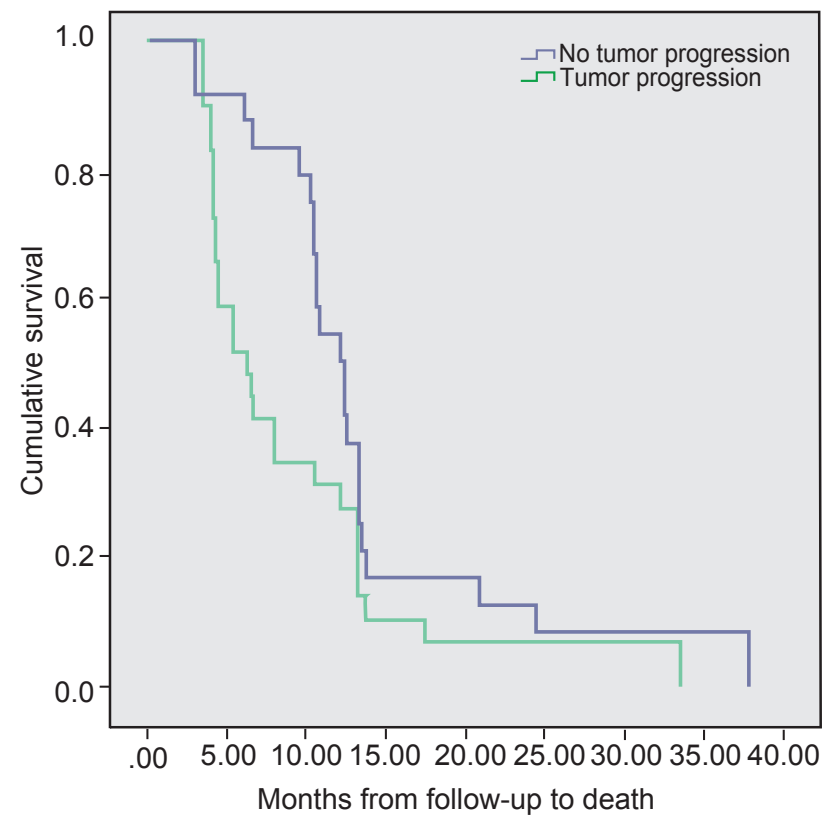

Fig. 1. Kaplan-Meier curve for overall survival from the time of stereotactic radiosurgery.

response and 13 lesions (24\%) with progressive/stable disease. In patients with complete/partial response, age $(p=0.752)$, histologies $(p=0.219)$, location of the brain metastases $(p=$ 0.257), and receipt of WBRT ( $p=0.908$ ) were not different than those with progressive/stable disease (Table 2). Mean target volume was significantly smaller in lesions with complete/ partial response than that in lesions with progressive/stable disease (2.07 vs. $11.95 \mathrm{~mL} ; p<0.001)$. Lesions with complete/ partial response received larger SRS doses (mean, 2,142 vs. $1,492 \mathrm{cGy} ; \mathrm{p}<0.001$ ) and coverage (mean, 96\% vs. 94\%; $p$ $=0.008)$ compared to those progressive/stable disease. There was no difference between the two groups for BED3 mean ( $p$ $=0.460)$ and BED10 mean $(p=0.325)$. In both groups, patients were more likely to receive single fractionated therapy; 11 lesions (84.6\%) in the group with progressive/stable disease and 25 lesions (80.7\%) in the group with complete/partial response $(p=0.445)$. At the time of SRS, 15 patients had extracranial metastases. There was no significant difference in the number of patients who presented with extracranial metastases between both groups $(p=0.914)$. Twelve patients received chemotherapy (either before and/or after SRS). Ten patients received immune checkpoint inhibitors. The number of patients receiving chemotherapy $(p=0.239)$ or immune checkpoint inhibitors ( $p=0.869)$ was not significantly different between the groups. 
Table 2. Demographic and clinical characteristics of patients with complete or no response

\begin{tabular}{|c|c|c|c|}
\hline Characteristic & $\mathrm{PD} / \mathrm{SD}$ & $\mathrm{CR} / \mathrm{PR}$ & $p$-value \\
\hline Age $(y r)$ & $53.10 \pm 12.66$ & $52.00 \pm 12.05$ & 0.752 \\
\hline Histology & & & 0.219 \\
\hline $\mathrm{RCC}$ & $5(22.73)$ & $12(38.71)$ & \\
\hline Melanoma & $17(77.27)$ & 19 ( 61.29) & \\
\hline WBRT & $11(50.00)$ & $16(51.61)$ & 0.908 \\
\hline Location & & & 0.257 \\
\hline Lt. frontal & $5(22.72)$ & $6(19.35)$ & \\
\hline Rt. frontal & $2(9.09)$ & 5 (16.13) & \\
\hline Lt. parietal & $5(22.72)$ & $6(19.35)$ & \\
\hline Rt. parietal & 4 (18.18) & 3 (9.68) & \\
\hline Lt. temporal & 3 (13.64) & 7 (22.58) & \\
\hline Rt. temporal & 3 (13.64) & $0(0)$ & \\
\hline Lt. occipital & $0(0)$ & $2(6.45)$ & \\
\hline Rt. occipital & $0(0)$ & $2(6.45)$ & \\
\hline Number of lesions & & & 0.445 \\
\hline Single & $20(90.91)$ & $25(80.65)$ & \\
\hline Multiple & $2(9.09)$ & $6(19.35)$ & \\
\hline SRS dose (cGy) & $1,492.3 \pm 357$ & $2,141.9 \pm 388$ & $<0.001$ \\
\hline $\mathrm{V}_{10 \mathrm{~Gy}}(\mathrm{~mL})$ & $21.36 \pm 14.55$ & $26.14 \pm 39.74$ & 0.593 \\
\hline$V_{12 G y}(m L)$ & $14.80 \pm 12.00$ & $20.64 \pm 31.42$ & 0.412 \\
\hline Coverage (\%) & $94.37 \pm 3.35$ & $96.44 \pm 2.10$ & 0.008 \\
\hline Target volume (mL) & $11.95 \pm 12.30$ & $2.07 \pm 3.16$ & $<0.001$ \\
\hline Tumor size $(\mathrm{cm})$ & & & $<0.001$ \\
\hline$<1$ & $9(40.91)$ & $28(90.32)$ & \\
\hline$>1$ & 13 (59.09) & $3(9.68)$ & \\
\hline Immune checkpoint inhibitor & $6(20)$ & $4(18.18)$ & 0.869 \\
\hline Chemotherapy & $18(58.06)$ & $17(77.27)$ & 0.239 \\
\hline Extracranial metastases on presentation & $25(80.65)$ & $18(81.82)$ & 0.914 \\
\hline BED10 & $53 \pm 24.47$ & $58 \pm 14.70$ & 0.325 \\
\hline BED3 & $134 \pm 69.74$ & $147 \pm 45.04$ & 0.460 \\
\hline
\end{tabular}

Values are presented as mean \pm standard deviation or number $(\%)$.

RCC, renal cell carcinoma; WBRT, whole brain radiation therapy; SRS, stereotactic radiosurgery; BED, biologically effective dose.

\section{Discussion and Conclusion}

Within a cohort of patients with radioresistant brain metastasis treated with SRS, we noted two main findings: the majority of patients had complete/partial response, and clinical factors such as tumor volume, SRS dose, and coverage are associated with complete/partial response.

In our series, complete/partial response was observed in $75 \%$ of the lesions treated with SRS. While this is within the range of other retrospective studies, it is unclear whether the response rates observed in these studies were complete/ partial [18-21]. Unfortunately, these retrospective studies used outdated ambiguous methodologies to assess local control, such as only measuring a single dimension or not even elaborating on their criteria for what was considered to be local control, making it difficult to generalize reported outcomes. In contrast to these studies, we utilized the standardized RECIST criteria to determine the tumor response to SRS. Furthermore, all patients included in our study were followed closely with surveillance brain MRIs every three months and symptomatic radiation necrosis was not observed.

In addition to investigating the treatment response rate, we 
also sought to determine factors associated with complete/ partial response. One of the key findings of our study is that smaller tumor volume is a positive predictor of complete/ partial response to SRS. This was also supported by prior studies $[12,19,21-24]$. Furthermore, our results also support the use of a higher SRS dose in brain metastases with melanoma or RCC, as reported in prior studies $[24,25]$. Based on the data from retrospective studies, the addition of WBRT did not consistently provide local control and survival benefit for radioresistant histologies [19-21,24,26-28]. Our results also suggest that the addition of WBRT did not provide significant improvement in response rate. Furthermore, higher coverage was associated with complete response in patients with radioresistant histologies.

In our study, there was no difference in survival in patients who achieved complete/partial response to SRS compared to those progressive/stable disease. Survival is a complex endpoint in patients with brain metastases and is influenced by factors such as performance status, age, number of metastases, primary diagnosis, and presence of extracranial metastases [29]. The extracranial metastases on presentation and the progression of the disease has a significant effect on survival in our study. SRS response rate may be more clinically relevant as improvement in systemic therapies continue to prolong survival in patients with radioresistant metastatic disease.

Limitations of our study include its retrospective design with inherent confounding factors and the clinical heterogeneity of patients with brain metastases. Another limitation of our study is that we did not examine the impact of systemic therapy, which could independently affect outcomes. The presence of additional unobserved confounding covariates may contribute to response rate, even with statistical methods that attempt to reduce the impact of selection bias on outcomes.

Compared to previous work, the added strengths of our study were the utilization of contemporary RECIST criteria to determine the response rate. In conclusion, SRS is an effective management option with up to 75\% response rate for radioresistant brain metastases. Tumor volume and radiation dose were predictors of response and can be used to guide decision-making for patients with radioresistant brain metastases.

\section{Conflict of Interest}

No potential conflict of interest relevant to this article was reported.

\section{References}

1. Nayak L, Lee EQ, Wen PY. Epidemiology of brain metastases. Curr Oncol Rep 2012;14:48-54.

2. Flanigan RC, Campbell SC, Clark Jl, Picken MM. Metastatic renal cell carcinoma. Curr Treat Options Oncol 2003;4:385-90.

3. Tas F. Metastatic behavior in melanoma: timing, pattern, survival, and influencing factors. J Oncol 2012;2012:647684.

4. Buchsbaum JC, Suh JH, Lee SY, Chidel MA, Greskovich JF, Barnett GH. Survival by radiation therapy oncology group recursive partitioning analysis class and treatment modality in patients with brain metastases from malignant melanoma: a retrospective study. Cancer 2002;94:2265-72.

5. Halperin EC, Harisiadis L. The role of radiation therapy in the management of metastatic renal cell carcinoma. Cancer 1983;51:614-7.

6. Maor MH, Frias AE, Oswald MJ. Palliative radiotherapy for brain metastases in renal carcinoma. Cancer 1988;62:1912-7.

7. Wronski M, Maor MH, Davis BJ, Sawaya R, Levin VA. External radiation of brain metastases from renal carcinoma: a retrospective study of 119 patients from the M. D. Anderson Cancer Center. Int J Radiat Oncol Biol Phys 1997;37:753-9.

8. Andrews DW, Scott CB, Sperduto PW, et al. Whole brain radiation therapy with or without stereotactic radiosurgery boost for patients with one to three brain metastases: phase III results of the RTOG 9508 randomised trial. Lancet 2004;363:1665-72.

9. Aoyama $H$, Shirato $H$, Tago M, et al. Stereotactic radiosurgery plus whole-brain radiation therapy vs stereotactic radiosurgery alone for treatment of brain metastases: a randomized controlled trial. JAMA 2006;295:2483-91.

10. Chang EL, Wefel JS, Hess KR, et al. Neurocognition in patients with brain metastases treated with radiosurgery or radiosurgery plus whole-brain irradiation: a randomised controlled trial. Lancet Oncol 2009;10:1037-44.

11. Brown PD, Ballman KV, Cerhan JH, et al. Postoperative stereotactic radiosurgery compared with whole brain radiotherapy for resected metastatic brain disease (NCCTG N107C/CEC-3): a multicentre, randomised, controlled, phase 3 trial. Lancet Oncol 2017;18:1049-60.

12. Lwu S, Goetz P, Monsalves E, et al. Stereotactic radiosurgery for the treatment of melanoma and renal cell carcinoma brain metastases. Oncol Rep 2013;29:407-12.

13. Ahmed KA, Sarangkasiri S, Chinnaiyan P, et al. Outcomes following hypofractionated stereotactic radiotherapy in the management of brain metastases. Am J Clin Oncol 2016;39:379-83. 
14. Rades D, Huttenlocher S, Gebauer N, et al. Impact of stereotactic radiosurgery dose on control of cerebral metastases from renal cell carcinoma. Anticancer Res 2015;35:3571-4.

15. Yaeh $A$, Nanda $T$, Jani $A$, et al. Control of brain metastases from radioresistant tumors treated by stereotactic radiosurgery. J Neurooncol 2015;124:507-14.

16. Lesueur P, Lequesne J, Barraux V, et al. Radiosurgery or hypofractionated stereotactic radiotherapy for brain metastases from radioresistant primaries (melanoma and renal cancer). Radiat Oncol 2018;13:138.

17. Eisenhauer EA, Therasse $P$, Bogaerts J, et al. New response evaluation criteria in solid tumours: revised RECIST guideline (version 1.1). Eur J Cancer 2009;45:228-47.

18. Grob JJ, Regis J, Laurans R, et al. Radiosurgery without whole brain radiotherapy in melanoma brain metastases. Eur J Cancer 1998;34:1187-92.

19. Mori Y, Kondziolka D, Flickinger JC, Kirkwood JM, Agarwala S, Lunsford LD. Stereotactic radiosurgery for cerebral metastatic melanoma: factors affecting local disease control and survival. Int J Radiat Oncol Biol Phys 1998;42:581-9.

20. Goyal LK, Suh JH, Reddy CA, Barnett GH. The role of whole brain radiotherapy and stereotactic radiosurgery on brain metastases from renal cell carcinoma. Int J Radiat Oncol Biol Phys 2000;47:1007-12.

21. Selek U, Chang EL, Hassenbusch SJ 3rd, et al. Stereotactic radiosurgical treatment in 103 patients for 153 cerebral melanoma metastases. Int J Radiat Oncol Biol Phys
2004;59:1097-106.

22. Shuto $T$, Inomori S, Fujino H, Nagano H. Gamma knife surgery for metastatic brain tumors from renal cell carcinoma. J Neurosurg 2006;105:555-60.

23. Mathieu D, Kondziolka D, Cooper PB, et al. Gamma knife radiosurgery for malignant melanoma brain metastases. Clin Neurosurg 2007:54:241-7.

24. Bagshaw HP, Ly D, Suneja G, Jensen RL, Shrieve DC. Local control of melanoma brain metastases treated with stereotactic radiosurgery. J Radiosurg SBRT 2016;4:181-90.

25. Lin HY, Watanabe $Y$, Cho LC, et al. Gamma knife stereotactic radiosurgery for renal cell carcinoma and melanoma brain metastases-comparison of dose response. J Radiosurg SBRT 2013;2:193-207.

26. Lo SS, Chang EL, Suh JH. Stereotactic radiosurgery with and without whole-brain radiotherapy for newly diagnosed brain metastases. Expert Rev Neurother 2005;5:487-95.

27. Chang EL, Selek U, Hassenbusch SJ 3rd, et al. Outcome variation among "radioresistant" brain metastases treated with stereotactic radiosurgery. Neurosurgery 2005;56:936-45.

28. Mingione V, Oliveira M, Prasad D, Steiner M, Steiner L. Gamma surgery for melanoma metastases in the brain. J Neurosurg 2002;96:544-51.

29. Sperduto PW, Chao ST, Sneed PK, et al. Diagnosis-specific prognostic factors, indexes, and treatment outcomes for patients with newly diagnosed brain metastases: a multiinstitutional analysis of 4,259 patients. Int J Radiat Oncol Biol Phys 2010;77:655-61. 